\title{
INFORMATION SECURITY ARCHITECTURE: AN INTEGRATED APPROACH TO SECURITY IN THE ORGANIZATION
}

\author{
by Jan Killmeyer Tudor \\ CRC Pr., September 2000, Hardcover - 424 pages, ISBN: 0849399882
}

$\mathrm{I}^{\mathrm{n}}$

n a comprehensive treatment of information security the author describes the five

key components of Information Security Architecture: organization/infrastructure, policy and procedure security baseline of system components, security awareness and training, and compliance.

The first chapter defines information security in terms of integrity, confidentiality, and availability, describes client-server environments and states issues in the development of strategic IT plans. Chapter 2 examines diverse issues of organizations such as information/resource ownership, roles of security officers, teams and committees, and human resources management issues. The next chapter is devoted to policies, standards and procedures. It covers policies on organizational security, confidentiality agreements, e-mail and Internet, security standards and procedures manuals.

Chapter 4 describes the baseline for security assessments, examining access control and program change management, LAN/WAN, operating systems and applications. It lists typical security issues in a sample baselining workplan. The next two chapters examine training and compliance issues. Chapter 7 looks at disaster recovery planning and seeks balances between security capability and cost, and between system performance and security. Chapter 8 presents main technological issues: encryption, firewalls, proxy servers, one-time passwords, and remote access servers. In the final chapter Tudor outlines the steps necessary to establish an integrated and effective security program.

The book contains a useful glossary and is accompanied by a CD with forms and worksheets to assist the reader in developing and implementing his or her own plan for information security in the organization. 